\title{
ENSAYO DE AUTOCRÍTICA: UNA PERSPECTIVA GENEALÓGICA SOBRE LA PRIMERA OBRA DE NIETZSCHE
}

An Attempt at Self-Criticism, a genealogical perspective on the first work of Nietzsche

\author{
Miguel Angel de Barrenechea
}

Universidade Federal do Estado de Rio de Janeiro (UNIRIO)

\begin{abstract}
RESUMEN: En este trabajo mi objetivo es analizar el conocido texto «Ensayo de autocrítica», que Nietzsche agregó - como una especie de prefacio o posfácio- a El nacimiento de la tragedia, dieciseis años después de la primera edición de su obra inaugural. Trataré de mostrar que el pensador alemán, en esa oportunidad, pretende emplear en si mismo el método de médico filósofo, realizando una observación clínica o genealógica sobre las motivaciones más profundas que intervinieron en la génesis de su libro de juventud. A partir de esa propuesta interpretativa, él pretendió detectar condicionamientos históricos, influencias políticas, artísticas y culturales que incidieron en un libro tan original, y aparentemente tan extemporáneo. Inclusive su farol genealógico lo lleva más allá: a intentar desvendar los impulsos personales y recónditos que incidieron en esa obra. Discute su propio estado de salud, sus propios instintos vitales que lo impulsaron a gestar un libro en el que cuestiona valores, ideales y conceptos fundamentales de sus contemporáneos.Palabras clave: autocrítica - genealogia - tragedia - médico-filósofo
\end{abstract}

ABSTRACT: In this paper my purpose is to investigate the well known «An attemp at selfcriticism», preface or afterword to The birth of tragedy added by Nietzsche sixteen years after the first edition of that inaugural work. I will try to show that the German thinker, on this oportunity, pretends to use himself as material for his «medical philosophers» method, using a clinic or genealogic observation about the deepest motivations envolved in the genesis of his youth book. From this interpretative proposal, he was trying to detect historical constraits and also political, artistic and cutural influences that incided in such an original and apparently extemporaneous book. In addition, his genealogic flair lids him far beyond: to figure out the personal and hidden impulses that afected this work and to speak on his own health condition together with his vital instincts that pushed him to create a book in which he questions the values, ideals and fundamental concepts of his generation. Keywords: self-criticism — geneaology — tragedy — medical philosopher

\section{INTRODUCCIÓN: LA TRAGEDIA Y LOS CUERPOS}

Desde el inicio mismo de su obra filosófica, Nietzsche se consideró un filósofo trágico, un pensador que se inspiró en una visión dionisiaca del mundo, oriunda de la civilización helénica, para abordar todas las cuestiones filosóficas, inclusive para evaluar y discutir los parámetros axiológicos vigentes en su propio tiempo. 
El pensador alemán adopta ideas de los griegos de la Antigüedad para cuestionar valores y conceptos que tenían vigencia en la modernidad. La visión trágica de la existencia se torna decisiva para discutir las concepciones dominantes entre sus contemporáneos. Desde 1869, en que redactó El nacimiento de la tragedia, hasta 1889, en sus últimos escritos, esa visión del mundo, que Nietzsche caracteriza como trágica, domina su pensamiento. El arte en general, y la perspectiva trágica en particular, serán las bases de su interpretación de la realidad, hasta el punto de denominar su filosofía «una metafísica de artista» ${ }^{1}$.

Ahora me parece importante destacar otro aspecto relevante de su filosofía que consiste en otorgar al cuerpo, a los instintos, a las pulsiones, un papel esencial para analizar todas las expresiones de la cultura, todas las cuestiones humanas ${ }^{2}$. El autor de El nacimiento de la tragedia sostiene que por detrás de todos los pensamientos, valores, concepciones del mundo, así como de todas las manifestaciones artísticas, jurídicas, económicas, etc., encontramos motivos corporales, fuerzas instintivas que están en la base de todos esos productos de la cultura. Nietzsche va a afirmar la primacía del cuerpo, el predominio interpretativo de los instintos que están en el origen de todo acto humano. Por eso, cuestiona las posturas idealistas que interpretan la cultura partiendo de motivaciones conscientes, racionales o espirituales. Por detrás de esas manifestaciones - muchas veces consideradas más elevadas, que serían de una naturaleza superior a todos los aspectos animales y naturales de los hombres- surge una clara percepción: en cada acción del hombre solo detectamos instintos, motivaciones corporales. Con otras palabras, Nietzsche adopta una perspectiva radicalmente inmanente y terrestre ${ }^{3}$. El hombre es un ser natural, un animal entre los animales, y su pensamiento no es más que un resultado de los instintos y fuerzas inconscientes que actúan en su cuerpo ${ }^{4}$. Así, la conciencia, el pensamiento,

1. Cf. «Ensayo de autocrítica», El nacimiento de la tragedia. Seguiré, en lineas generales, la versión canónica de las obras completas de Nietzsche: Sämtliche Werke, Berlin/New York: Gruyter \& Co., 1967-1977. Para ayudar a mi comprensión de las traducciones al español me apoyé fundamentalmente en versiones de las obras nietzscheanas en portugués, principalmente las realizadas por el reconocido traductor Paulo César de Sosa, en Companhia das Letras. En el caso específico de El nacimiento de la tragedia, emplée también la traducción al español realizada por Agustín Izquierdo (Madrid: Edaf, 1998). Para facilitar la lectura, a partir de ahora, cuando me refiera a El nacimiento de la tragedia paso a emplear las siglas NT y a continuación cito el capítulo de la obra. Sobre la concepción nietzscheana entendida como metafísica de artista, veamos el comentario de Fink: «En el fenómeno trágico se percibe la verdadera naturaleza de la realidad; el tema estético adquiere [...] la condición de un principio ontológico fundamental; el arte, la poesía trágica, se torna [...] la llave que le abre la vida esencial del mundo. El arte es erigido en organon de la filosofia...» (E. Fink, A filosofia de Nietzsche, trad. de J. L. Duarte Peixoto, Lisboa: Presença, 1983, p. 17).

2. En ese sentido, Assoun llega a caracterizar el pensamiento nieztscheano como «una filosofía de los instintos». Cf. P. L. Assoun, Freud y Nietzsche, México, 1984, p. 77. En mi libro Nietzsche e o corpo, Rio de Janeiro: 7Letras, 2009, abordé, de forma detallada, la relevancia que tiene el cuerpo en la obra de Nietzsche y especialmente mostré su estatuto de «hilo conductor» para desarrollar todas las cuestiones filosóficas.

3. Löwith afirma que, en la concepción inmanente, terrestre de Nietzsche, es necesario «recolocar al hombre en la naturaleza; triunfar sobre muchas interpretaciones y connotaciones vanidosas y exaltadas, que hasta el momento fueron garabateadas y pintadas sobre el eterno texto del homo natura...» (K. Löwith, «Nietzsche e a completude do ateísmo», en S. Marton, Nietzsche hoje, São Paulo: Brasiliense, 1985, p. 145).

4. Lemm muestra como Nietzsche coloca en primer plano, de forma clara y elocuente, la condición animal y mundana del hombre, ya que «cree que la vida humana es inseparable de la vida del 
las ideas son de naturaleza corporal, inmanente. Estos conceptos —el privilegio comprensivo de los instintos, la primacía interpretativa del cuerpo, orientarán toda interpretación nietzscheana de la civilización, toda lectura del devenir del hombre.

Desde los primeros escritos de Nietzsche, incluyendo su libro inaugural El nacimiento de la tragedia, vemos ese privilegio otorgado a la acción de los instintos, de todas las fuerzas corporales ${ }^{5}$. La tesis de la primacía cognoscitiva del cuerpo, sustentada a lo largo de toda su obra, queda paradigmaticamente establecida en un conocido aforismo de 1885, en el que se afirma que debemos adoptar el «cuerpo como hilo conductor» (Am Leitfadem des Leibes), como base de todo conocimiento ${ }^{6}$.

De esa forma, el autor de El nacimiento... emplea nociones vinculadas al cuerpo para analizar todas las actividades humanas. Al abordar todas las cuestiones del hombre utiliza categorías como salud y enfermedad, fuerza y debilidad. En ese sentido, Nietzsche emplea, a partir del bienio 1872-1873, el concepto de médico de la cultura (Der Philosoph als Arzt der Kultur) o médico filósofo7. Según esa perspectiva, la tarea primordial de la filosofía consiste en indagar las condiciones vitales en que surgieron los diversos pensamientos, los valores que condicionaron al hombre, a lo largo del tiempo. Tendremos que indagar cuáles fueron los impulsos, las fuerzas que los originaron, para establecer si esas expresiones del hombre son síntomas de fuerza o de debilidad, de vida ascendente o descendente; en suma, es necesario detectar clínicamente si indican salud o enfermedad.

Esta estrategia interpretativa será consolidada a lo largo de toda la obra de Nietzsche. Poco a poco, la cuestion del cuerpo y los instintos se torna cada vez más frecuente en sus textos. Vemos surgir imágenes peculiares y elocuentes que aluden a la necesidad de determinar las motivaciones inconscientes que condicionan la vida del hombre. Una metáfora significativa la encontramos en el prefacio de Aurora, en el primer aforismo, cuando se alude al «filósofo topo»: aquel que debe horadar el subsuelo, el subterraneo de la vida humana, las fuerzas ignotas que operan en el hombre. Ese filósofo topo debe intentar penetrar en esas motivaciones más profundas de la condición humana. Para realizar esa difícil tarea, debe privarse de aire, de luz; ese esfuerzo le permitirá aproximarse a los impulsos más distantes y ocultos del ser humano: lo inconsciente, lo irracional, los aspectos ocultos de la vida conciente. Por ese motivo, el aludido filósofo topo puede ser caracterizado como un genuino hermeneuta de los «bajos fondos» ${ }^{8}$.

En La ciencia jovial Nietzsche continúa ahondando la singular tesis sobre la primacía del cuerpo para interpretar todas las cuestiones filosóficas. En ese libro

animal y del conjunto del mundo orgánico e inorgânico». V. Lemm, Nietzsche Animal Philosophy: culture, politics, and the animality of the human being, Nueva York: Fordham UP, 2009, p. 3.

5. En El nacimiento de la tragedia, como vemos ya en su primer capítulo, los instintos apolíneos y dionisíacos están en la base del arte trágico, así como en todas las manifestaciones de la cultura griega. Cf. NT, 1.

6. Cf. FP, Otoño, 2 [91].

7. Wotling destaca la aparición del concepto de médico de la civilización, que será relevante en el pensamiento de Nietzsche, a partir de 1872-1873: «Desde sus primeros textos, el proyecto filosófico es determinado nítidamente: efectivamente, en las notas del invierno 1872-1873 define por primera vez la tarea específica del filósofo através del modelo médico: 'El filósofo como médico de la civilización'» (P. Wotling, Nietzsche et le problème de la civilisation, París: PUF, 1985, pp. 111-112).

8. En Aurora, prefacio, 1, el filósofo topo es considerado «un 'ser subterráneo', un ser que perfora, que escarba» los aspectos más obscuros del hombre. 
reedita la sugestiva imagen que ya había forjado en 1872-1873: del «médico filósofo» o del filósofo como médico de la civilización. En el prefacio de esa obra destaca la necesidad de que surjan pensadores que actúen como genuinos «médicos» o «terapeutas» de la cultura. Es necesario que aparezcan filósofos que tengan un especial farol crítico para determinar las motivaciones corporales que subyacen en las grandes producciones del hombre, hasta aquellas consideradas más «ideales» o «elevadas», como el arte, la religión, la filosofía, la moral, etc. En todas ellas no encontramos motivaciones abstractas, elevados conceptos o nociones de un supuesto carácter trascendente. No; por detrás de todos esos ideales vemos tendencias humanas, demasiado humanas; apenas detectamos fuerzas inmanentes que pueden ser entendidas como síntomas de salud o enfermedad: manifestaciones de fuerza, potencia, ampliación de la vida o, al contrario, debilidad, impotencia o degragación de la existencia ${ }^{9}$. Es decir, el médico filósofo se confronta con esas ideas a partir del parámetro de la salud; no es su objetivo discutir la verdad o la falsedad de esos enunciados, su tarea esencial consiste en determinar el tipo de vida que expresan esas ideas, si son manifestaciones patológicas o indicios de vigor corporal.

La propuesta de interpretación corporal e instintiva de toda las cuestiones humanas encuentra un novedoso procedimiento metodológico denominado genealogía en la etapa final de la obra nietzscheana; esa metodología aparece claramente detallada en la obra Genealogía de la moral. La genealogía pretende analizar las condiciones de surgimento de todas las morales, de todos los valores gestados por el hombre a lo largo de su historia. El método genealógico indaga cómo, cuándo, en qué momento y en qué condiciones nació una determinada tabla de valores, o una concepción moral. ¿Cuáles fueron las circunstancias, las fuerzas y estados corporales que dieron lugar a las diversas instituciones erigidas por el hombre: moral, derecho, justicia, etc.? Nietzsche analizará el surgimiento de diversas morales, de diversas religiones, intentando determinar las fuerzas que las originaron. En cada aspecto del hombre — conciencia, responsabilidad, memoria, razón— no operan supuestos motivos ideales, metafísicos o transcendentes, sino un complejo juego de impulsos, de motivos de origen corporal, terrestre ${ }^{10}$.

En resumen, en la trayectoría filosófica de Nietzsche el cuerpo y todas las manifestaciones instintivas son considerados los aspectos más nítidos, los más seguros para abordar todas las cuestiones filosóficas. El propio Nietzsche realizará permanentemente una reinterpretación de sus obras, de sus ideas, de sus diversas posturas teóricas y personales a partir del análisis corporal, genealógico, de todos sus actos. En ese sentido, considero importante analizar ahora cómo el filósofo realiza una profunda autocrítica de la gestación de su primera obra: El nacimiento de la tragedia. En 1886, escribe el «Ensayo de autocrítica», presentado como prefacio o posfacio de El nacimiento..., para realizar un balance de su primer libro,

9. «Yo aún espero que un médico filósofo, en el sentido excepcional del término - alguien que detecte el problema de la salud general de un pueblo, una época, de una raza, de la humanidad...» (La ciencia jovial, prefacio, 2).

10. En Genealogía de la moral, prológo, 3, Nietzsche pregunta: «¿Bajo qué condiciones el hombre inventó para sí los juicios de valor 'bien' y 'mal'? [...] ¿Son indicios de miseria, empobrecimiento, degeneración de la vida? O al contrario, ¿̇e revela em ellos la plenitud, la fuerza, la voluntad de vida, su coraje, su certeza, su futuro?». 
tan instigante y osado, a partir del «hilo conductor del cuerpo». La propuesta es asumir una genuina tarea terapéutica, propia de un severo «médico filosófico» que realizará nada menos que el diagnóstico de sí mismo.

\section{¿POR QUÉ UN ENSAYO DE AUTOCRÍTICA?}

Nietzsche, en 1886, elabora ese texto que pretende ser revelador sobre todos los motivos que lo impulsaron a escribir El nacimiento de la tragedia. Se trataba de un balance de las ideas, los valores, la visión del mundo que, en 1869, lo llevaron a gestar una obra singular, insólita, sobre los griegos y la tragedia. Ese primer libro fue calificado como insólito por ser el producto de un joven filólogo, que se desempeñaba justamente como profesor de Filología en Basilea, pero que se alejó totalmente del terreno de la filología. Sorprendentemente, ese escritor incipiente creó algo totalmente distinto a un tratado o una investigación estrictamente filológica. El joven catedrático presentó una inusitada visión sobre el origen de la tragedia, completamente distante de las interpretaciones consideradas canónicas sobre el arte griego. Elaboró una concepción singular sobre el nacimiento del arte helénico, atribuyendo su origen a la confrontación de instintos, al juego de fuerzas oriundas de la naturaleza: al conflicto entre los instintos apolíneos y dionisíacos. Se trataba de una tesis novedosa que atribuye a estados corporales, a manifestaciones de la naturaliza, la procedencia del arte griego. Denomina apolíneo y dionisíaco a los estados de sueño y de embriaguez, de placidez onírica y de exaltación orgiástica. En otras palabras, Nietzsche interpreta la tragedia helénica, así como las diversas manifestaciones de esa cultura, como el producto de instintos estéticos, oriundos de la naturaleza.

Es conocido el impacto que provocó esa singular tesis entre los académicos, entre los profesionales de la filología y entre otros teóricos de la época. El nacimiento de la tragedia fue descalificado, estigmatizado y considerado como un libro completamente anticientífico, no filológico, como una creación totalmente arbitraria y fantasiosa, como una interpretación casi delirante, sin cualquier fundamentación rigurosa, carente de argumentos teóricos o apoyo en documentos o en otros elementos probatorios. La condena fue casi unánime entre los académicos ${ }^{11}$; su libro estaba prácticamente destinado al olvido, pero un detalle importante lo salvó del ostracismo total. El libro estaba dedicado a Wagner, gran músico, reconocido por su relevante obra artística y también por sus escritos sobre arte. En esa época, inicio de la década de 1870, Wagner tenía gran prestigio y muchos seguidores; el libro del joven filólogo exaltaba profundamente la música del creador de Las bodas de Lutero; llegaba a considerar el arte wagneriano como una obra suprema de la Modernidad. El joven Nietzsche no pasó totalmente desapercibido al publicar El nacimiento... porque el círculo de allegados a Wagner consideró ese

11. Wilamowitz, renombrado filólogo de la época de Nietzsche, autoridad incontestable en el ámbito académico y científico de esos años, considera El nacimiento... como una obra arbitraria, delirante, sin base científica. En este sentido, veamos como Machado alude a la crítica del citado filólogo: «Nietzsche no es un científico [para Wilamowitz], es decir, un verdadero filólogo [...], es un místico, el predicador de una religión dionisíaca y, por tanto, no debería estar en la universidad» (R. Machado, Nietzsche e a polêmica sobre O nascimento da tragédia, Rio de Janeiro: Zahar, 2005, p. 25). 
libro justamente como una especie de manifiesto wagneriano, como una pieza de exaltación del músico. Así, fue interpretada como una obra al servicio del gran músico. Fue entonces defendida como tal, como filosofía o filología wagneriana. Y por ese mismo motivo fue considerada como una obra nacionalista, romántica, pesimista. En el aspecto propiamente filosófico, resultaba evidente la influencia de Schopenhauer, cuya concepción metafísica parecía estar en la base de El nacimiento... Sus categorías dicotómicas de voluntad y representación parecían ser el sustento principal de la visión metafísica de ese libro juvenil, en que el arte - fundamento de la metafísica de artista- era considerado el organon de acceso a la genuina realidad. La dicotomía Apolo-Dioniso aparecía como un correlato de los conceptos de representación-voluntad, apariencia y esencia, originários del autor de El mundo como voluntad y representación. También podía percibirse que el pesimismo schopenhaueriano resonaba claramente en la comprensión del fenómeno trágico que Nietzsche sustentaba en 1869.

En resumen, la obra inaugural de Nietzsche, más allá del impacto que trajo aparejado, como inusitada interpretación del fenómeno trágico, fue nitidamente asociada a la concepción wagneriana y schopenhaueriana del arte, de la cultura, del mundo. Por eso, el joven autor fue calificado de romántico, pesimista, nacionalista. Su original forma de ver la tragedia, los griegos, la naturaleza fue distorcionada y encubierta por esas notables influencias. En 1886, un Nietzsche adulto reevalúa su trayecto teórico y quiere entender los motivos, las influencias, las circunstancias que cercaron su primer libro. También quiere separar las cosas: indagar cual era, de hecho, su visión, más allá de las influencias de Wagner, de Schopenhauer, de los nacionalistas, de los románticos etc. En otras palabras, él quiere establecer lo que era genuinamente de él, lo que era propio, en la visión de mundo que el joven Nietzsche sustentó en El nacimiento de la tragedia. Para resolver esa cuestión, el propio pensador, en el «Ensayo de autocrítica», opera como médico filósofo y tenta realizar una especie de genealogía o terapéutica de si mismo.

\section{GRIEGOS Y MODERNOS, PESIMISMO Y OPTIMISMO,} HOMBRES TEÓRICOS Y TRÁGICOS

$\mathrm{El}$ «Ensayo de autocrítica» se divide en siete capítulos. En ese sucinto trabajo vemos una notable organicidad, una gran concisión, en que el filósofo intenta reflexionar sobre las motivaciones principales que incidieron en la gestación de su primer libro. No solo eso. Al analizar los factores, las circunstancias, las ideas que tejía en 1869 sobre los griegos, percibimos algo mucho más amplio. Encontramos un balance crítico del contexto histórico y personal del autor, e inclusive vemos uma aguda visión sobre la concepción metafísica schopenhaueriana que adoptó, en muchos sentidos, en la obra de juventud. Nietzsche reflexiona sobre lo que denominó metafísica de artista, cuestionando, el papel otorgado al arte en esa concepción juvenil, entendida como la propia vía de acceso a la esencia de la realidad. Confrontaba, en aquella obra, esa visión con la metafísica racional que surge a partir de Sócrates, en que el pensador ateniense considera que la ciencia puede llegar no solo a conocer el ser, sino hasta corregir el ser, esto es, se trataba de una perspectiva en la cual la razón forjaría un mundo diferente, un locus ideal, perfecto e inmutable, situado más allá del mundo imperfecto y efímero en que vivimos. 
En «Ensayo de autocrítica», se sostiene que, a partir del socratismo, comienza a consolidarse una concepción optimista. Se trataba del optimismo teórico, de la creencia en que la ciencia, a través del hilo conductor de la causalidad, nos conducirá a conocer todos los aspectos de la realidad. La oposición del hombre moderno respecto de la visión de los antiguos se agudiza: Nietzsche enfatiza que los helenos arcaicos, los griegos trágicos, eran justamente pesimistas, no creían en los poderes ilimitados de la razón. Es propio de la visión trágica una evaluación pesimista de todo lo real, en la que se reconoce los límites de todo lo que existe; todas las formas finitas han de perecer; no obstante, más allá de la destrucción individual, continúa exuberante la vida: toda individualidad es eliminada; sin embargo, la naturaleza permanece eterna, invicta. Nietzsche afirma que esa aceptación de la destrucción individual y la afirmación de la naturaleza como un todo está en la base del ritual dionisíaco. Dioniso encarna el retorno permanente de todas las fuerzas inmanentes. Se trataba de un pesimismo de la fuerza porque esa convicción le permitía al griego, en los rituales y en las representaciones trágicas, celebrar y consagrar la destrucción y recreación permanente de todo lo que existe. Ritualización de la destrucción y reconstrucción de todas las formas finitas, encarnada en el símbolo del jubiloso Dioniso descuartizado, que retorna, que renace en toda primavera.

En «Ensayo...» Nietzsche continúa confrontando la visión pesimista de los griegos arcaicos con la postura del hombre teórico moderno. Detalla con claridad las diferencias que estableció entre pesimismo y optimismo, entre arte trágico y ciencia. El filósofo recuerda también que en su obra inaugural hay otra tesis relevante; en su primer libro enfatiza claramente su visión crítica sobre la moral occidental. La moral dicotómica, que separa bien y mal, es cuestionada como una forma totalmente antivital de lidiar con la existencia humana. La moral es denunciada como una tendencia que condena toda manifestación sensible, toda belleza, todo lo es que impulsivo y orgánico. El cristianismo, a su vez, es considerado una concepción moralista al extremo, antivital al extremo. Nietzsche reconoce que en El nacimiento... el cristianismo fue abordado de una forma casi velada, que fue casi ignorado, pero en «Ensayo...» no quiere dejar pasar la oportunidad de cuestionarlo. Se trataba de la religión que condena todo arte, toda manifestación afectiva y sensorial. Al estar basado en una concepción escatológica, que solo valoriza un más allá, un mundo ideal, alejado de la tierra, de los sentidos, de las pasiones, condena todo lo que es oriundo del mundo, de lo inmanente; calumnia todo lo que es vital y orgánico. En resumen, en el posfacio de 1886 a El nacimiento, la visión trágica es confrontada con la ciencia, con la moral, con la concepción cristiana.

\section{ENSAYO DE AUTOCRÍTICA: CONTEXTO E INFLUENCIAS EN EL JOVEN NIETZSCHE}

Nietzsche, en el primer capítulo de «Ensayo...», alude al contexto en el que fue realizada su obra. Destaca que Europa vivía la guerra franco-prusiana, y que él participó, de alguna forma, en ese conflicto bélico como enfermero. Una enfermedad lo sacó, providencialmente, de la proximidad a la peripecia bélica. De todas formas, no se considera ajeno a lo que acontece en ese momento. Padeció, vivió de cerca las contingencias dramáticas de la guerra, de la muerte, del dolor que afectaba a sus contemporáneos. En ese sentido, el entonces joven filólogo recuerda un detalle singular: cuando redactaba El nacimiento... estaba dentro de los muros de la for- 
taleza de Metz, en la que hacía poco se habían producido decisivos escarceos de la contienda bélica. En ese lugar justamente se decidió la confrontación, antes del cese el fuego, previo a la derrota de los franceses. Y en ese lugar, el joven Nietzsche estaba justamente reflexionando sobre los griegos, sobre el origen de la música y de la tragedia helénica. Se confrontaba con cuestiones procedentes de un pensar distante, arcaico, pero no se desentendía de los problemas de sus contemporáneos; meditaba sobre la civilización griega, aun estando muy cerca de las peripecias y del ímpetu bélico de los hombres modernos. Así, a lo largo del «Ensayo...», el autor tiene clara conciencia de esa antinomia entre griegos trágicos y modernos optimistas. El pensar trágico y la visión moderna están siempre en cuestión. La reflexión sobre los griegos no le impide ser testigo - y partícipe- de todo lo que acontece con sus contemporaneos; el pensamiento trágico no le impide pensar el ahora, las ideas de ese momento histórico. Al contrario, ese contraste se torna importante, revelador. Discutir sobre los antiguos, le permite cuestionar valores e ideas modernos, así como lo instiga a pensar en un futuro inminente, en que podría resurgir la concepción trágica, en que podría establecerse una nueva era trágica.

Percibimos que la cuestión política aparece en rápidos enunciados, en sintéticas alusiones a lo largo del «Ensayo...»; no obstante, en el sexto y el séptimo capítulos, Nietzsche aborda con más detalle las influencias sociales y políticas que condicionaron El nacimiento... Señala que, en aquel momento, la exaltación nacionalista germánica, la valorización de una música narcótica, el esteticismo exagerado, la afectación romática fueron influencias notables en ese joven Nietzsche. El pensador cree, en 1886, que esos factores lo llevaron a desvirtuar, a confundirse en su interpretación del fenómeno dionisiaco griego. El pesimismo trágico helénico fue distorsionado por esas tendencias que valorizaban lo nacional, lo oscuro, lo exageradamente afectivo y melancólico. La propia metafísica de artista es considerada poco justificada, arbitraria, carente de justificaciones, razones, argumentos.

Es interesante notar como el filósofo alemán alude a los impulsos, a los afectos, a las cuestiones vitales que se tornaron factores esenciales para meditar sobre todos los temas tratados en su libro. La problemática de la salud y la enfermedad aparecían como guías para entender las cuestiones del arte y de la cultura griega. Recuerda algunas como la de la aparente paradoja de un pueblo, como el helénico, que estando en su plenitud, en el vigor de sus años jóvenes, al mismo tiempo forjó una concepción pesimista. La tragedia parece expresar estados contradictorios de juventud y senilidad, de fuerza y patología. Por eso, Nietzsche pregunta si es posible que haya una locura del exceso, de la fuerza, de la salud. Actúa como un genuino médico filósofo al detectar que en el fenómeno dionisiaco se manifiesta un estado fisiológico de excitación, de exaltación, prácticamente de locura. Su diagnóstico detecta una locura del exceso, de la juventud, de la superabundancia de fuerzas, pues llevó a aquellos antiguos griegos, no a la decadencia, sino a la creación, a la gestación de grandes obras, como el exuberante ritual trágico. No se trata de enfermedad, en el sentido de retracción vital, de desgaste fisiológico, sino de un pathos de la plenitud, del derroche de fuerzas y de potencia, que lleva a la creación de obras de excelencia. 
¿Cuál era el estado de salud del propio Nietzsche?: ¿en qué estado vital se encontraba al escribir El nacimiento...? El filósofo reconoce su ímpetu desmedido, su aptitud inmadura, exagerada, exaltada, cuando redacta su primera obra. Elaboró un libro con los excesos juveniles pero, pese a ello, abordó una cuestión senil, profunda, seria, radical. Era un problema que exigía gran madurez, y más al ser encarado por un autor aún muy inmaduro intelectualmente y hasta afectivamente. Por ese motivo, también reconoce que actuaba como alguien que se consideraba un iniciado, como un místico, como un profeta de un dios desconocido. La ausencia de madurez intelectual determinó que, al considerarse un iniciado o portavoz de una religión desconocida, no sintiese la necesidad de justificar, de demostrar sus intuiciones, sus visiones. No solo actuaba como un entusiasta religioso, pretendidamente iluminado por una divindad ignota, sino que procedía como un artista incipiente. Actuaba como un poeta, como un entusiasta que hablaba para un grupo selecto de artistas, para estetas sui generis que podían adorar a ese dios «desconocido". Reconoce que ese libro juvenil —en el pleno sentido de la palabra-, gestado en esas supuestas visiones iniciáticas, era practicamente algo imposible, es decir, injustificable, insostenible desde el punto de vista literario y filosófico. Estaba mal escrito, era exagerado, arbitrario y afectado. En 1886, Nietzsche reconoce que, antes de dar a luz esa obra prematura de 1869, habría sido mejor cantar; habría sido mejor poetizar que pretender escribir sobre un fenómeno, sobre una experiencia que no conseguía traducir en argumentos, al carecer de justificaciones racionales. Reconoce también que las explicaciones aducidas en $E l$ nacimiento, muchas veces estaban camufladas bajo el disfraz del académico, de un pseudo filólogo. Admite que, víctima de esos arrebatos místicos, de la exaltación poética, ni siquiera consiguió presentar razones filológicas, que supuestamente eran las que esgrimía para hablar de su religión dionisiaca.

Después de cuestionar los excesos poéticos y juveniles que dominaron $\mathrm{El}$ nacimiento de la tragedia, Nietzsche continúa indagando otros problemas que detectó en esa obra inaugural. En el centro de las cuestiones abordadas en «Ensayo de autocrítica», más allá del fenómeno dionisíaco, de la ciencia moderna, del optimismo y del pesimismo, sin duda, estaban Wagner y Schopenhauer. En la primera parte del texto, ambos aparecen muy tímidamente, muy discretamente. El gran músico inclusive es citado rápidamente y no es cuestionado de forma clara y explícita, como vemos, por ejemplo, en obras posteriores, como Nietzsche contra Wagner o El caso Wagner. En esos libros, el músico es criticado duramente, pues Nietzsche ve en él un sintoma claro característico de los hombres modernos: un verdadero narcótico, una forma de anestesiar los sentidos. Hay una mención muy rápida a Wagner en el segundo capítulo de «Ensayo...», cuando comenta el éxito de El nacimiento..., que aconteció junto al «gran artista Richard Wagner» ${ }^{12}$. Vemos que al dirigirse al músico lo hará de forma respetuosa, hasta elogiosa; esa postura llama la atención, pues contrasta con su visión final sobre la obra y

12. «... dado su éxito [de El nacimiento de la tragedia] (en especial junto al gran artista Richard Wagner, a quien se dirigía como para establecer un diálogo...» («Ensayo de autocrítica», 2, en NT). 
la personalidad de Wagner. En el penúltimo capítulo de «Ensayo...» reaparece, de una forma un poco velada, la cuestión del autor de Parsifal, cuando Nietzsche realiza un profundo cuestionamiento a la música alemana. Es seguro que Nietzsche alude principalmente a Wagner, aunque curiosamente no lo cita, no lo menciona de forma explícita. Parece que, de alguna manera, preserva la imagen del músico, que en otros textos cuestiona con inusitada contundencia. De todas formas, critica duramente la música alemana en general. La música que, en esa época, era asociada con el «ser alemán». No podemos dejar de lado que el propio Nietzsche, en el texto de 1869 , publicado en 1872 , no solo exalta al músico alemán, sino que también coloca en primer plano la cuestión alemana: El nacimiento... se dedicaría a un "problema seriamente alemán» ${ }^{13}$. No obstante lo que se critica explícitamente en el texto de 1886 es la música alemana —seguramente alude a la música wagneriana, pero no lo dice, no lo explicita en ese momento , que opera como un narcótico, como un anestésico, destrozando los nervios y obnubilando los sentidos. Surge una mezcla temible: romanticismo, música alemana, nacionalismo y bebida. Nietzsche recuerda que sus connacionales aprecian mucho las bebidas, los narcóticos. De ahí el valor de la música narcótica. De todas formas, el cuestionamiento también va dirigido a sí mismo: también él estaba narcotizado, obnubilado; era nacionalista, wagneriano, romántico, en resumen: actuaba, en líneas generales, como un joven germánico típico, un joven profesor universitario de los años de la década de los setenta.

Aún en el capítulo sexto de «Ensayo...» encontramos el cuestionamiento de Nietzsche a los fundamentos teóricos de su libro de juventud. Nietzsche muestra que en esa época estaba influenciado por tendencias metafísicas oriundas del kantismo y de la visión schopenhaueriana de mundo. De esas tendencias adoptó las categorías dicotómicas, como esencia y apariencia, fenómeno y númeno, voluntad y representación. Advierte que no encontró, en aquel momento, «un lenguaje próprio» para expresar sus intuiciones singulares sobre el fenómeno dionisíaco. Por eso, adoptó las ideas y el aparato conceptual, principalmente, de Schopenhauer. Y así distorsionó notablemente su singular visión del problema griego $^{14}$. Inclusive, al acompañar la interpretación pesimista de Schopenhauer no consiguió penetrar en las cuestiones más profundas de la visión trágica. Para el filósofo de El mundo..., la vida no sería digna de ser vivida. La concepción trágica llevaría a la resignación, a la renuncia al mundo ${ }^{15}$. Por eso, en «Ensayo...», se condena claramente la intepretación pesimista de Schopenhauer. Para Nietzsche, la tragedia está muy lejos de llevar a la resignación, a la renuncia a la vida: «... ide qué diferente forma hablaba Dioniso conmigo!, iqué lejos de mí estaba toda

13. «... tal vez quede claro [...] con qué problema seriamente alemán tenemos que vernoslas, el que está situado por nosotros en el centro de las esperanzas alemanas...» (Prefacio a Richard Wagner, en NT).

14. «... hay algo mucho peor en el libro, que ahora lamento mucho más, que fue oscurecer y arruinar con fórmulas schopenhauerianas algunos presentimientos dionisiacos: a saber, ique arruiné de modo absoluto el grandioso problema griego, tal como él se me había aparecido, por la injerencia de cosas más modernas!». («Ensayo de autocrítica», 6, en NT).

15. Nietzsche recuerda un pasaje del segundo libro de El mundo como voluntad y representación, en el que Schopenhauer sostiene que el genuino conocimiento del mundo y de la vida humana lleva a la resignación y a la renuncia, cuando constatamos la falta de sentido de todo lo que existe. Cf. «Ensayo de autocrítica», 6 . 
esa visión resignada!» ${ }^{16}$. Al contrario, el fenómeno dionisiaco, en que el héroe individual siempre es destruido, muestra que, más allá de esa supresión de la individualidad, resurge siempre la vida eterna, la naturaleza retorna más allá de la aniquilación de la existencia individual. Entonces, lo esencial de lo dionisiaco es celebrar la vida de forma irrestricta, conmemorar todas las formas finitas, en su precariedad y al mismo tiempo en su exuberancia. Se trata de un pesimismo de la fuerza, en que la existencia es afirmada en todos sus matices, en el dolor y la destrucción, en la muerte y la finitud, pero principalmente en la alegría, en la floración, en la celebración de todo lo existente.

\section{PESIMISMO DE LA FUERZA: LA RISA Y LA ALEGRÍA}

En el último capítulo del «Ensayo», Nietzsche muestra realmente cómo deshacer la confusión, las distorsiones sobre su concepción trágica, que generó tantos malentendidos en la época de la publicación de El nacimiento de la tragedia. Para eso, necesitó reevaluar el momento histórico en que escribió su obra, así como repensar las influencias de Wagner y Schopenhauer, y destapar sus propios condicionamientos personales, subjetivos. Lo que el filósofo va a presentar, en el último capítulo de su balance crítico, después de ofrecer una perspectiva genealógica, terapéutica, de su primera visión trágica, es justamente la concepción dionisiaca que él sostiene ya en la fase más avanzada de su obra. Es decir, después de eliminar los malentendidos, característicos de esa obra juvenil, aún resta por aclarar cuál sería la postura que emerge después de ese ejercicio autocrítico, dieciseis años después. Nietzsche se pregunta qué aconteció con aquel filósofo que adoptó una visión pesimista del mundo, calcada de la filosofía trágica de los helenos. ¿̇En qué consistiria, años después, su óptica trágica? ¿Habría una perspectiva pesimista más allá de la visión romántica y melancólica de los modernos? Nietzsche pretende mostrar cómo su concepción trágica, en 1886, indica caminos totalmente diferentes de los transitados por el nacionalismo, el romanticismo, el pesimismo y la música moderna. Muestra que la perspectiva helénica dionisiaca está muy lejos de la óptica wagneriana o schopenhaueriana. Sostiene que el arte trágico no lleva a un consuelo metafísico, en el sentido de negar la vida, como en la visión de Schopenhauer. También quiere dejar claro que no pretende ofrecer una salida escatológica, como la adoptada por muchos románticos que acabaron adhiriéndose al cristianismo. El filósofo trágico se opone a distintas instituciones modernas, cuestiona por ejemplo las propuestas políticas democráticas, en que se procura una igualdad a cualquier precio, en que se niegan las diferencias, las características de cada individualidad. También critica el nacionalismo, que restringe una visión más amplia, más integral de la existencia, valorizando abstracciones como la nación, el ciudadano, el pueblo, etc. Es importante percibir que esas críticas políticas aparecen de forma rápida, como una especie de telón de fondo para colocar en primer plano la concepción más propiamente filosófica que estaba por detrás de esas ideas.

Finalmente, Nietzsche alude a Así habló Zaratustra. Transcribe un párrafo importante de esa obra para mostrar lo esencial de su propuesta trágica, conforme

16. «Ensayo de autocrítica», 6 . 
a su comprensión de lo trágico ya en la fase avanzada de su obra. El consuelo, el contento metafísico que el artista dionisiaco ofrece, es un consuelo de «este lado». A diferencia de los románticos, de los wagnerianos, que acaban por adoptar una visión escatológica, una fuga del mundo, una recusación de la tierra, Nietzsche defiende, en 1886, un consuelo que celebra el mundo, que afirma lo inmanente: «iNo! Vosotros deberíais aprender primero el arte del consuelo de este lado de acá $[\ldots]{ }^{17}$. Y, en primer lugar, reconoce el cuerpo como nuestro aspecto esencial. «Ensayo de autocrítica» concluye con palabras de Zaratustra que celebran el cuerpo, la inmanencia, la tierra. Exalta la fidelidad a la tierra. Después de realizar una aguda autocrítica, a partir de una visión genealógica o terapéutica, todo lo corporal debe ser rescatado. Lo romántico, lo idealista, lo de más allá son subterfugios, engaños, ilusiones propios de una tradición metafísica idealista. Podemos decir que son síntomas de un cuerpo cansado, que son manifestaciones de organismos enfermos y desgastados. Por el contrario, en Zaratustra encontramos claramente expresada — con un lenguaje marcadamente poético— la visión más potente del fenómeno trágico sostenida por Nietzsche. En ese texto de elevada calidad literaria hay genuinamente un canto a la fidelidad al cuerpo, a la celebración de los instintos, a la consagración de la tierra.

Añado ahora, en esta parte final del artículo, algunas de las imágenes a través de las cuales, vinculadas al personaje de Zaratustra, se presenta una nueva visión trágica, totalmente singular. Ese personaje habla de lo que es del cuerpo y de la tierra, y no del más allá, de lo ideal. Zaratustra habla de las piernas, recuerda que con piernas firmes andamos. Con piernas firmes, pero al mismo tiempo ligeras. Por eso, Zaratustra es como un bailarín que se desliza levemente; tan levemente que parece volar, que parece tener alas, que parece ser un pájaro. Imágenes que sin duda nos transportan a lo esencial de la afirmación trágica del mundo y de la vida. Las piernas de Zaratustra son terrestres y, al mismo tiempo, ligeras y aladas. Piernas que comulgan con una cabeza, también terrestre, también alada. Y esa afirmación total de lo inmanente es coronada por Zaratustra. Él lleva una corona en su cabeza. Una corona de sonrisas, de risas. Metáforas de la plenitud que alude a este mundo finito. Pues en la finitud es donde damos saltos laterales, no saltos hacia otros mundos. Zaratustra ama los saltos laterales ${ }^{18}$. El «Ensayo de autocrítica» cierra su telón discursivo e imaginario con palabras del singular personaje persa. La evaluación de su libro de juventud, la autocrítica de sus tesis sobre los griegos, la tragedia, los modernos, la ciencia, el arte, etc., finaliza aludiendo a la risa como suprema afirmación. Zaratustra, al reír, es trágico porque dice sí a todo lo que existe: es leve, alegre. Además es santo. Aquí la santidad adopta un peculiar significado, no tiene nada que ver con el ascetismo, con la negación de los sentidos, con la realización de milagros: santidad es la total aceptación de lo existente. Es la risa que se manifesta como un sí sagrado.

17. Cf. «Ensayo de autocrítica», 7 .

18. Cf. ibid. 